\title{
Time Dependent Influence of Rotating Magnetic Field on Bacterial Cellulose
}

\author{
Karol Fijałkowski, ${ }^{1}$ Rafał Rakoczy, ${ }^{2}$ Anna Żywicka, ${ }^{1}$ Radosław Drozd, ${ }^{1}$ \\ Beata Zielińska, ${ }^{3}$ Karolina Wenelska, ${ }^{3}$ Krzysztof Cendrowski, ${ }^{3}$ Dorota Peitler, ${ }^{1}$ \\ Marian Kordas, ${ }^{2}$ Maciej Konopacki, ${ }^{2}$ and Ewa Mijowska ${ }^{3}$ \\ ${ }^{1}$ Department of Immunology, Microbiology and Physiological Chemistry, West Pomeranian University of Technology in Szczecin, \\ Piastów 45, 70-311 Szczecin, Poland \\ ${ }^{2}$ Institute of Chemical Engineering and Environmental Protection Processes, West Pomeranian University of Technology in Szczecin, \\ Piastów 42, 70-311 Szczecin, Poland \\ ${ }^{3}$ Division of Nanotechnology, West Pomeranian University of Technology in Szczecin, Piastów 45, 70-311 Szczecin, Poland
}

Correspondence should be addressed to Karol Fijałkowski; karol.fijalkowski@zut.edu.pl

Received 15 October 2015; Revised 15 December 2015; Accepted 21 December 2015

Academic Editor: Antje Potthast

Copyright ( 2016 Karol Fijałkowski et al. This is an open access article distributed under the Creative Commons Attribution License, which permits unrestricted use, distribution, and reproduction in any medium, provided the original work is properly cited.

\begin{abstract}
The aim of the study was to assess the influence of rotating magnetic field (RMF) on the morphology, physicochemical properties, and the water holding capacity of bacterial cellulose (BC) synthetized by Gluconacetobacter xylinus. The cultures of G. xylinus were exposed to RMF of frequency that equals $50 \mathrm{~Hz}$ and magnetic induction $34 \mathrm{mT}$ for 3,5, and 7 days during cultivation at $28^{\circ} \mathrm{C}$ in the customized RMF exposure system. It was revealed that $\mathrm{BC}$ exposed for 3 days to RMF exhibited the highest water retention capacity as compared to the samples exposed for 5 and 7 days. The observation was confirmed for both the control and RMF exposed BC. It was proved that the $\mathrm{BC}$ exposed samples showed up to $26 \%$ higher water retention capacity as compared to the control samples. These samples also required the highest temperature to release the water molecules. Such findings agreed with the observation via SEM examination which revealed that the structure of BC synthesized for 7 days was more compacted than the sample exposed to RMF for 3 days. Furthermore, the analysis of $2 \mathrm{D}$ correlation of Fourier transform infrared spectra demonstrated the impact of $\mathrm{RMF}$ exposure on the dynamics of $\mathrm{BC}$ microfibers crystallinity formation.
\end{abstract}

\section{Introduction}

Bacterial cellulose (BC) is an exopolysaccharide which can be produced by various species of bacteria; however only Gluconacetobacter xylinus has been considered as a model microorganism for its production and analysis [1]. The cellulose produced by G. xylinus exhibits high purity, high degree of crystallinity, high density, good shape retention, high water binding capacity, and higher surface area as compared to the plant cellulose $[2,3]$. Due to these properties the $\mathrm{BC}$ has a wide range of potential applications including artificial skin [2, 4], dental implants [5], dialysis membrane $[5,6]$, coatings for cardiovascular stents [5], membranes for tissue-guided regeneration $[2,5]$, controlled-drug release carriers [5], vascular prosthetic devices [7], scaffolds for tissue engineering [2], wound dressing [5, 8, 9], and artificial blood vessels $[10,11]$. Besides the applications in biomedical areas, $\mathrm{BC}$ membrane has also been used as separation medium for water treatment [12], carrier of battery fluids [13], viscosity modifier [4], biological substrate medium [14], or food or food substitute [4]. Additionally, a few new areas have been explored on developing the distinctive features of this novel biomaterial. The integration of the optical activity [15], electrical conductivity [16], magnetic nanoparticles [17], or photocatalytic degradation [18] materials to the $\mathrm{BC}$ matrix for various applications has also been studied.

In order to fulfill the requirements of diverse applications, the $\mathrm{BC}$ should be synthesized in the strictly defined culture conditions or subjected to different specific modifications [3]. It was previously shown that the biosynthesis of $\mathrm{BC}$ by 
microorganisms is directly influenced by the composition (nutrients nature) and conditions (static and dynamic) of culture medium, affecting BC yield, its macromorphology, and the arrangement of cellulose fibrils [19]. As reported by several authors, the BC obtained in the static culture conditions show enhanced arrangement of the $\mathrm{BC}$ fibril layer in comparison to the $\mathrm{BC}$ synthesized in dynamic culture conditions [20]. The latter one displays lower crystallinity, lower polymerization degree, and lower yield. Furthermore, it forms structure with high porosity and large water holding capacity [21]. It is also found that high oxygen content could disturb the arrangement process of the BC crystalline fibril structure [22].

The modification of $\mathrm{BC}$ can be performed during its biogenesis by the introduction of different substances into the BC-producing bacterium growth medium (hemicelluloses, cellulose derivatives, drugs, and dyes) or by modification of bacterial cells [23]. The modification affects, for example, the aggregation of nanofibers, crystallinity, crystallite size, polymerization, thermal stability, strength, porosity, roughness, morphology, and density [24]. The other approaches for modification of cellulose (plant or bacterial) include the use of physical factors, such as ultrasound irradiation (or sonication) $[25,26]$, static magnetic field (SMF) [27-30], or rotating magnetic field (RMF) exposure [31].

The influence of the physical factors on the growth and cell metabolic activity can be attributed to its effects on mixing of the bioliquids at microlevels. The microscopic mixing can influence the transfer process between the cell surface and the liquid phase, affecting the cell transport mechanism [32]. Moreover, the RMF can cause relative motions of the medium and the magnetic flux lines [33]. The associated currents can be induced in the culture medium as a consequence of the magnetic field because the culture medium contains various cations, for example, $\mathrm{Na}^{+}, \mathrm{K}^{+}, \mathrm{Mg}^{2+}$, and $\mathrm{NH}^{4+}$, and the associated anions, for example, sulphate, phosphate, and chlorate, along with the microbial cells that contain various components including ionic solutions, proteins, and lipids. These factors are susceptible to the influence of magnetic or induced electric fields [33, 34]. Previous studies have also found that the cellulose nanocrystals have a negative diamagnetic anisotropy [35] and that they are oriented perpendicularly to the magnetic field direction $[27-29,36]$. Therefore, it was suggested that MFs may alter the cellulose nanocrystals orientation $[37,38]$.

In our previous study, we demonstrated that the constant exposure to the RMF for 3 days resulted in the cellulose yield characterized by higher water absorption, lower density, and less interassociated microfibrils comparing to the unexposed control [31]. However, it should be noticed that the stimulating effect of the RMF on the functional parameters of microorganisms was shown to be dependent on the time of magnetic field exposition [39, 40]. Similarly, the time of $G$. xylinus cultivation during which the $\mathrm{BC}$ biosynthesis occurs is considered as one of the crucial parameters affecting the properties of this material [22]. As reported by Hesse and Kondo [41] the cellulose secretion is randomly deposited behind the microorganism to produce the membrane of certain porosity and three-dimensional network. The movement of single cell is caused by the inverse force of the secretion of the cellulose nanofibers. Therefore, it can be assumed that the application of MF for different exposure time during the cellulose biosynthesis may influence the microstructure of the synthetized BC and thus its physical and chemical properties. Thus, in the current work, the effect of exposure time $(3,5$, and 7 days) of the cellulose producing G. xylinus to RMF of frequency of $50 \mathrm{~Hz}$ and magnetic induction of $34 \mathrm{mT}$ was assessed. The main purpose of this study was to examine whether a long-term (up to 7 days) exposure of $G$. xylinus to the RMF affects the morphology, physicochemical properties, and the water capacity of the synthetized cellulose. The obtained BC samples were analyzed using a set of analytical methods including Attenuated Total Reflectance Fourier Transform Infrared Spectroscopy (ATR-FTIR), Xray diffraction (XRD) method, scanning electron microscopy (SEM), and dry/wet weight assessment and were compared to properties of cellulose produced in standard conditions (unexposed to RMF, the control).

\section{Materials and Methods}

2.1. BC Biosynthesis in RMF. The experiment was performed using the self-designed RMF exposure system adapted for the biological studies presented in Figure 1 and described in the previous work [31].

Briefly, the reference strain of $G$. xylinus (Deutsche Sammlung von Mikroorganismen und Zellkulturen, DSM 46604) was cultivated in the stationary conditions using a Hestrin-Schramm (HS) medium composed of glucose, $2 \mathrm{w} / \mathrm{v} \%$, yeast extract, $0.5 \mathrm{w} / \mathrm{v} \%$, bacto-peptone, $0.5 \mathrm{w} / \mathrm{v} \%$, citric acid, $0.115 \mathrm{w} / \mathrm{v} \%, \mathrm{Na}_{2} \mathrm{HPO}_{4}, 0.27 \mathrm{w} / \mathrm{v} \%, \mathrm{MgSO}_{4} \cdot 7 \mathrm{H}_{2} \mathrm{O}$, $0.05 \mathrm{w} / \mathrm{v} \%$, bacteriological agar, $2 \% \mathrm{w} / \mathrm{v}$, and ethanol, $1 \mathrm{v} / \mathrm{v} \%$, for 7 days at $28^{\circ} \mathrm{C}$. Prior to the experiment, the 7-day culture was shaken and then $100 \mu \mathrm{L}$ of the obtained bacterial suspension was used to inoculate $25 \mathrm{~mL}$ HS medium in $50 \mathrm{~mL}$ plastic tubes $(3.8 \mathrm{~cm}$ diameter) (Polypropylene Conical Centrifuge Tube, Becton Dickinson and Company, USA) containing bacteria being exposed to the RMF. The frequency of the generated RMF and the magnetic induction was equal to $50 \mathrm{~Hz}$ and $34 \mathrm{mT}$, respectively. The magnetic exposure was carried out for 7 days at $28^{\circ} \mathrm{C}$. The cellulose pellicles were collected in $3 \mathrm{rd}$, 5th, and 7 th day of the experiment. Each tube was used only once.

The same bacterial strain, incubated in the same time and under the same conditions but unexposed to the RMF, was generated as the control of experiment.

2.2. The Preparation of BC Samples. The BC was harvested from the medium and purified by the triplicate treatment with $0.1 \mathrm{M} \mathrm{NaOH}$ at $80^{\circ} \mathrm{C}$ for $30 \mathrm{~min}$ to remove the bacterial cells and medium components and then rinsed with water. The obtained cellulose was dried in an oven (EV-50, Trade Raypa, Spain) at $60^{\circ} \mathrm{C}$ until a constant weight was reached and investigated as described below. 


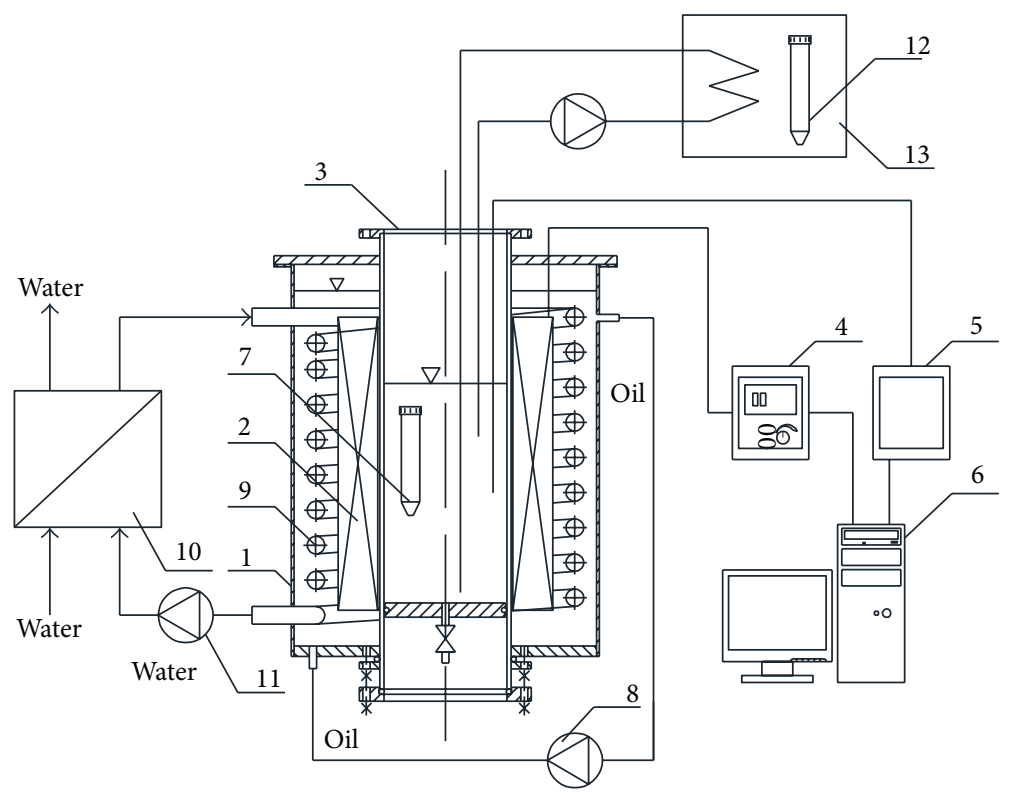

FIGURE 1: Experimental set-up: 1-housing; 2-generator of RMF; 3-cylindrical tube with bottom; 4-a.c. transistorized inverter; 5-thermal control system; 6-personal computer; 7-test tube; 8-circulating pump for oil; 9-cooling coil; 10-heat exchanger; 11-circulating pump for coolant; 12-control tube; 13-water bath.

\subsection{Attenuated Total Reflectance Fourier Transform Infrared} Spectroscopy (ATR-FTIR). IR spectra of bacterial cellulose were performed by the ATR-FTIR method, using ALPHA FT-IR Spectrometer (Burker Co., Germany) with an DTGS detector and the platinum-ATR-sampling module with the robust diamond crystal and variable angle incidence of the beam. The measurements were carried out at an angle of $30^{\circ}$. The spectra were collected in the range of $4000-400 \mathrm{~cm}^{-1}$. For each of the samples 32 scans of the resolution of $2 \mathrm{~cm}^{-1}$ were performed. The spectra were collected and processed initially using the Omnic Software. The ATR-FTIR spectra of $\mathrm{BC}$ were analyzed by means of the two-dimensional correlation (2D correlation) analysis using 2Dshige software (Shigeaki Morita, Kwansei-Gakuin University, Nishinomiya, Japan). For the 2D correlation analysis, the areas of the spectra were restricted to the range between $1800 \mathrm{~cm}^{-1}$ and $650 \mathrm{~cm}^{-1}$, normalized at the frequency band of $660 \mathrm{~cm}^{-1}$ using the methodology described by Liu et al. [42, 43] and analyzed using Origin Pro 8 software.

The crystallinity index was calculated using the ratio of absorbance values for peaks $1430 / 900\left(\mathrm{Cr} . \mathrm{R}_{1}\right)$ and 1370/2900 $\left(\mathrm{Cr} . \mathrm{R}_{2}\right)$. The fraction of the cellulose $I_{\beta}$ was calculated from ATR-FTIR spectra according to the method described by Kataoka and Kondo [44]. The area of the peaks at $A 710$ $\left(710 \mathrm{~cm}^{-1}\right)$ for $I_{\beta}$ and at $A 750\left(750 \mathrm{~cm}^{-1}\right)$ for $I_{\alpha}$ was determined from the spectra deconvoluted in Peakfit software. The percentage of $I_{\beta}$ was calculated according to the formula:

$$
\% I_{\beta}=\frac{A 710}{(A 710+A 750)} 100 \%
$$

2.4. X-Ray Diffraction (XRD). The crystallographic structure of $\mathrm{BC}$ was evaluated by $\mathrm{X}$-ray diffraction analysis (Philips,
X'Pert PRO diffractometer). The $\mathrm{CuK}_{\alpha}$ radiation $\left(\mathrm{K}_{\alpha 1}=\right.$ $1.54056 \AA ; \mathrm{K}_{\alpha 2}=1.54439 \AA ; 35 \mathrm{kV}$ and $30 \mathrm{~mA}$ ) was applied. The $\mathrm{K}_{\beta}$ and $\mathrm{K}_{\alpha 2}$ were removed with the filter and the numerical procedure of Rachinger's methods, respectively. The configuration of goniometer was Bragg-Brentano. The diffracted intensity of $\mathrm{CuK}_{\alpha}$ radiation was measured in a $2 \theta$ range between 5 and 35 with a step of 0.02 . The Philips HighScore plus software was used for data evaluation. Moreover, the average size of the crystallites $(D)$ was calculated using the Scherrer equation [45] based on the reflection of plane of 200:

$$
D=\frac{K \lambda}{\cos \theta \sqrt{B^{2}-b^{2}}},
$$

where $b$ is the line width originating solely from instrumental broadening; $B$ is the broadening of the diffraction line measured at half maximum intensity (FWHM); $K$ is shape factor (it is equal to 0.94) [45]; $\lambda$ is X-ray wavelength (it is equal to $1.54 \AA$ ); $\theta$ is the Bragg angle corresponding to the (200) plane.

The shape factor 0.94 was assumed and broadening of the reflex originating solely from instrumental broadening and the size of the crystallites. The instrumental broadening was estimated by the measurement of silicon reference sample for several reflection and interpolation for 200 reflex.

2.5. Scanning Electron Microscopy (SEM). The morphology of BC samples was investigated by scanning electron microscopy (TESCAN, VEGA SBU3). SEM images of asprepared $\mathrm{BC}$ samples were acquired with $30 \mathrm{kV}$ acceleration voltage.

2.6. Swelling Study. For the swelling study the cellulose pellicles were cut into $1 \mathrm{~cm}$ square samples and dried at 
TABLE 1: The BC crystallinity index from ATR-FTIR spectra and $\%$ of $I_{\beta}$ allomorph form content.

\begin{tabular}{lcccc}
\hline Days of BC synthesis & Sample & Cr.R $_{1} 1427 / 900$ & Cr. $_{2} 1360 / 2900$ & $\% I_{\beta}$ \\
\hline 3 & RMF exposed & 3.14 & 3.08 & 3.13 \\
& Control & 3.16 & 2.77 & 46.8 \\
\hline \multirow{2}{*}{5} & RMF exposed & 3.24 & 3.06 & 49.8 \\
\hline \multirow{2}{*}{7} & Control & 3.25 & 3.27 & 48.5 \\
& RMF exposed & 3.38 & 3.30 & 44.8 \\
\hline
\end{tabular}

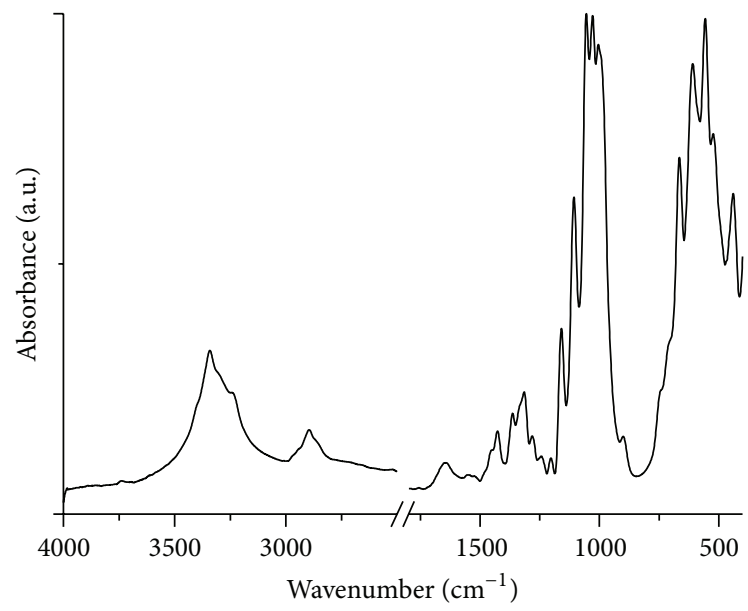

FIGURE 2: The representative ATR-FTIR spectra profile of analyzed $\mathrm{BC}$ samples. The noisy region from carbon dioxide and air influence in range from $2000 \mathrm{~cm}^{-1}$ to $2500 \mathrm{~cm}^{-1}$ was excluded from the graph.

$60^{\circ} \mathrm{C}$ for $6 \mathrm{~h}$ to remove any water content and weighed using analytical balance (accuracy $0.0001 \mathrm{~g}$ ). Then samples were immersed in distilled water until a constant weight was reached (15 min). Afterwards, they were wiped carefully with filter paper and weighed again on the analytical balance. Each swelling experiment was taken in triplicate. The results are shown as percentage of swelling ratio (\%SR) and calculated using the formula:

$$
\% \mathrm{SR}=\frac{(\text { wet weight }- \text { dry weight })}{\text { dry weight }} 100 \%
$$

2.7. Water Holding Capacity. The cellulose pellicles were cut into small equal pieces, immersed in a distilled water for $15 \mathrm{~min}$, wiped carefully with filter paper, and placed into the thermogravimetric analyzer (DTA-Q600 SDT TA). The analysis was performed in air flow $(40 \mathrm{~mL} / \mathrm{min})$ from room temperature to $120^{\circ} \mathrm{C}$, with the heating rate of $1^{\circ} \mathrm{C} / \mathrm{min}$. The results are shown as percentage of the sample weight loss versus the temperature. The initial weight of $\mathrm{BC}$ immersed in water was treated as $100 \%$.

\section{Results}

3.1. Analysis of ATR-FTIR Spectra. The chemical structure of different BC samples was studied by ATR-FTIR.
The spectrum shown in Figure 2 is characteristic absorption bands of $\mathrm{BC}$ functional groups indicating that the typical cellulose was produced [20].

In all the analyzed samples the bands that involve $\mathrm{OH}$ bending in the range of 400 to $700 \mathrm{~cm}^{-1}$ were found. The characteristic broad band present at $\approx 900 \mathrm{~cm}^{-1}$ corresponds to the beta glycosidic bond between the subunits of glucose. The presence of typical components of the glucose structure as (C-O, stretch) primary alcohols, antisymmetric out-ofphase stretching in pyranose ring, and C-O-C antisymmetric bridge stretching bands is confirmed in the range of 1058 to $1168 \mathrm{~cm}^{-1}$ indicated. The next region from 1200 to $1700 \mathrm{~cm}^{-1}$ corresponds to $\mathrm{CH}_{2}$ bending $\left(\approx 1370 \mathrm{~cm}^{-1}\right)$ and $\mathrm{CH}_{2}$ symmetric bending $\left(\approx 1430 \mathrm{~cm}^{-1}\right)$. The band at $\approx 1640 \mathrm{~cm}^{-1}$ indicates $\mathrm{H}-\mathrm{O}-\mathrm{H}$ bending of the absorbed water. The mode at $2900 \mathrm{~cm}^{-1}$ is related to the stretching of the $\mathrm{CH}_{2}$ and $\mathrm{CH}_{3}$ of the pyranose ring and the broad band at $3350 \mathrm{~cm}^{-1}$ is attributed to the $\mathrm{OH}$ stretching from intramolecular hydrogen bonds [46].

The analysis of the content of BC $I_{\alpha}$ and $I_{\beta}$ crystalline phases showed similar amount of $\% I_{\beta}$ allomorph form for both RMF exposed and the control BC (Table 1). The highest level of $I_{\beta}$ was recorded for BC samples synthesized for 5 days. It was also shown that the values of crystallinity indexes Cr. $\mathrm{R}_{1}$ and Cr. $\mathrm{R}_{2}$ calculated for the RMF exposed and control BC did not significantly vary in time.

A synchronous 2D correlation spectrum exhibits the similarity between the sequential variations of the spectra intensities [47]. As reported by Noda [48], the 2D correlation analysis is suitable to establish the spectral band assignments but also to monitor the complex sequence of the events arising from the changes in the polymers. Furthermore, the 2D correlation method could be applied to understand the compositional and structural changes within the developed fibers in the presence of an external perturbation. A synchronous spectrum is a symmetric spectrum with respect to a diagonal line corresponding to the spectral coordinates [49]. The regions of a dynamic spectrum which change intensity to a greater extent are represented by the stronger autopeaks (diagonal peaks). The cross-peaks located at the off-diagonal positions of synchronous $2 \mathrm{D}$ correlation spectrum represent the simultaneous changes of the spectral signals at two different wave numbers [48].

Figure 3 shows the differences in the intensity of the bands pointing on the structural changes in $\mathrm{BC}$ occurring in the following days of the synthesis. The successive decrease 


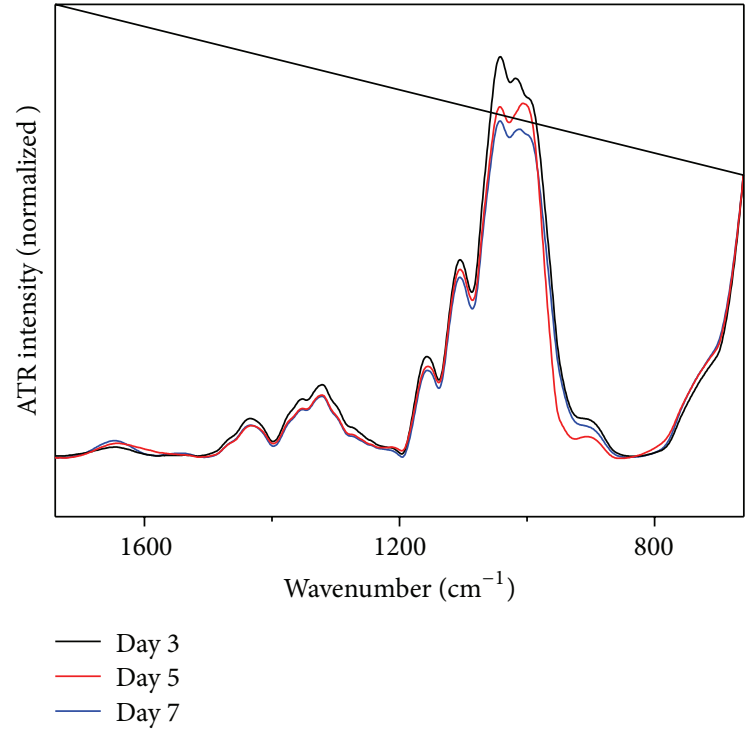

(a)

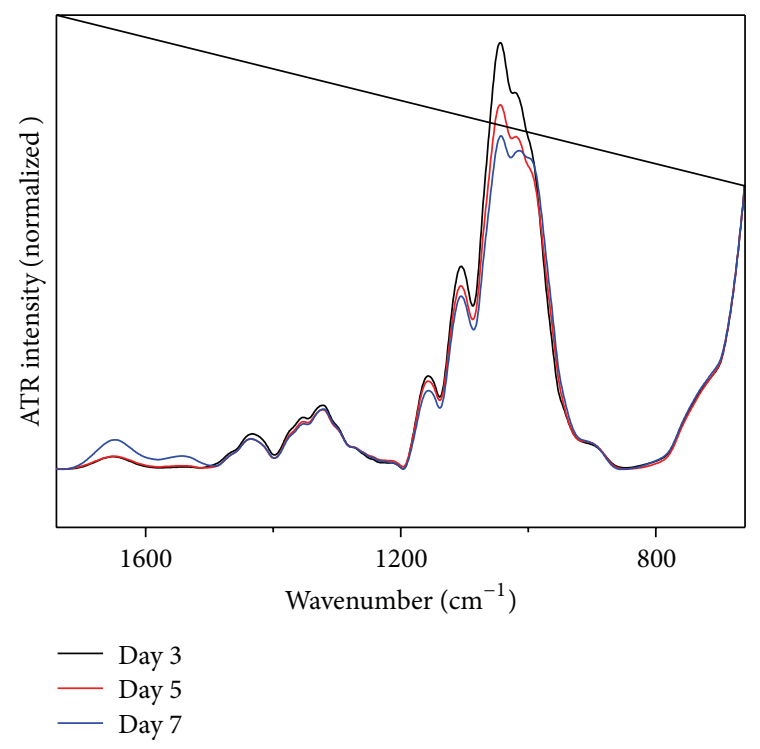

(b)

FIgURE 3: ATR-FTIR spectra of (a) control and (b) RMF exposed BC pellicles in the range from $1800 \mathrm{~cm}^{-1}$ to $660 \mathrm{~cm}^{-1}$.

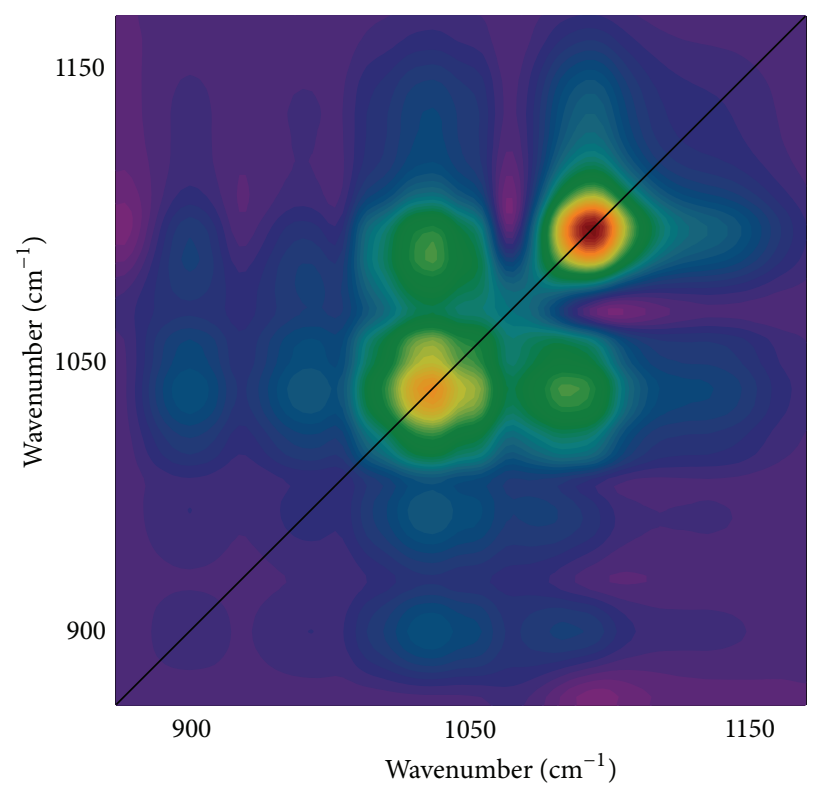

(a)

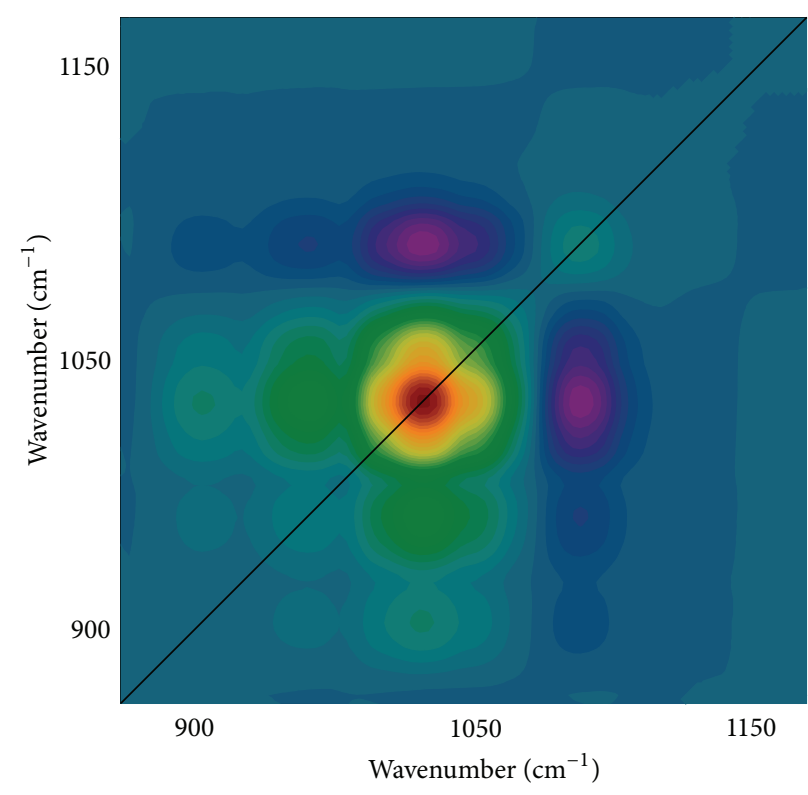

(b)

FIGURE 4: ATR-FTIR synchronous 2D correlation spectrum of (a) control and (b) RMF exposed BC samples. The degree of correlation is visualized with the rainbow color map. The cold colors represent negative correlation, and the warm colors represent positive correlation.

in the intensity of the bands in the range from $1200 \mathrm{~cm}^{-1}$ to $800 \mathrm{~cm}^{-1}$ of the spectra region is related to the changes in structure and composition of the cellulose.

In the current study, the analysis of synchronous $2 \mathrm{D}$ correlation of ATR-FTIR spectra calculated from the time dependent ATR-FTIR spectra obtained from the region 850$1150 \mathrm{~cm}^{-1}$ was used to determine the $\mathrm{BC}$ maturity related to its microfibers crystallinity. The $2 \mathrm{D}$ correlations spectra are presented in Figures 4(a) and 4(b) for control BC and
RMF exposed BC, respectively. As shown, RMF exposed samples were characterized by more dynamic changes in the range of analyzed spectra in comparison to the control BC. Two characteristic autopeaks at $\approx 968 \mathrm{~cm}^{-1}$ and $\approx 1042 \mathrm{~cm}^{-1}$ were observed on the diagonal of this plot, which indicate positive trend in altering their intensity. It might result from the presence of $\mathrm{C}-\mathrm{O}$ stretching mode of primary alcohols $(-\mathrm{C} 6 \mathrm{H} 2-\mathrm{O} 6 \mathrm{H})$, in which band at $968 \mathrm{~cm}^{-1}$ is characteristic for BC with a high degree of crystallinity, whereas 


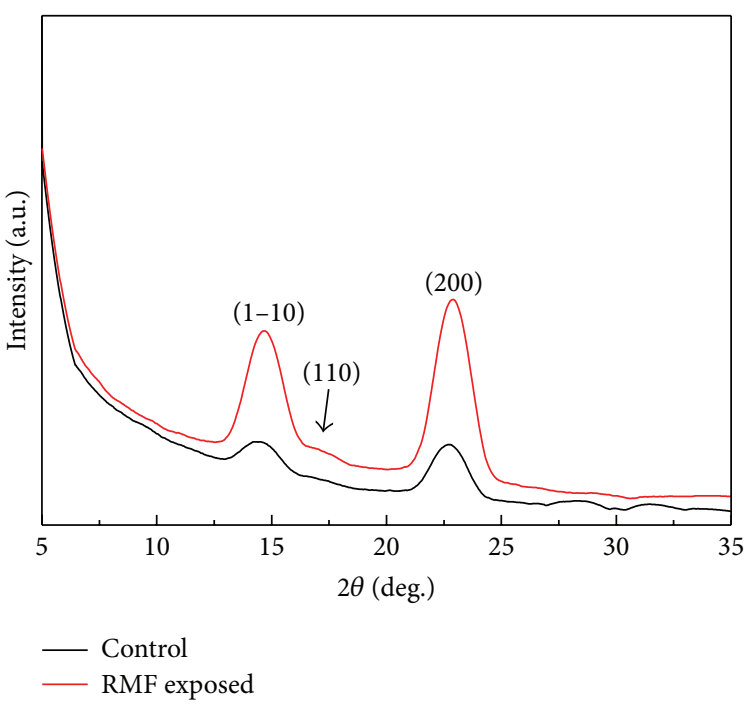

(a)

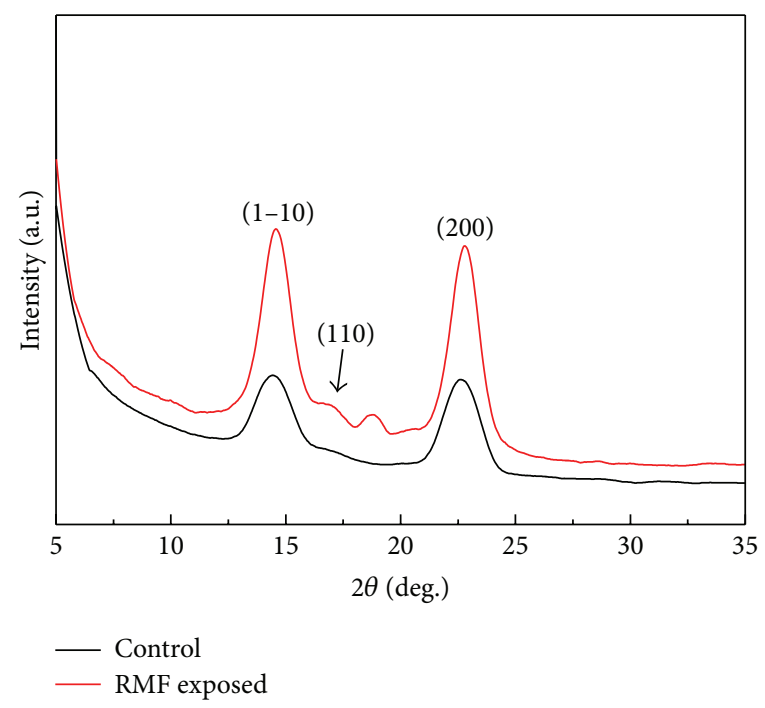

(b)

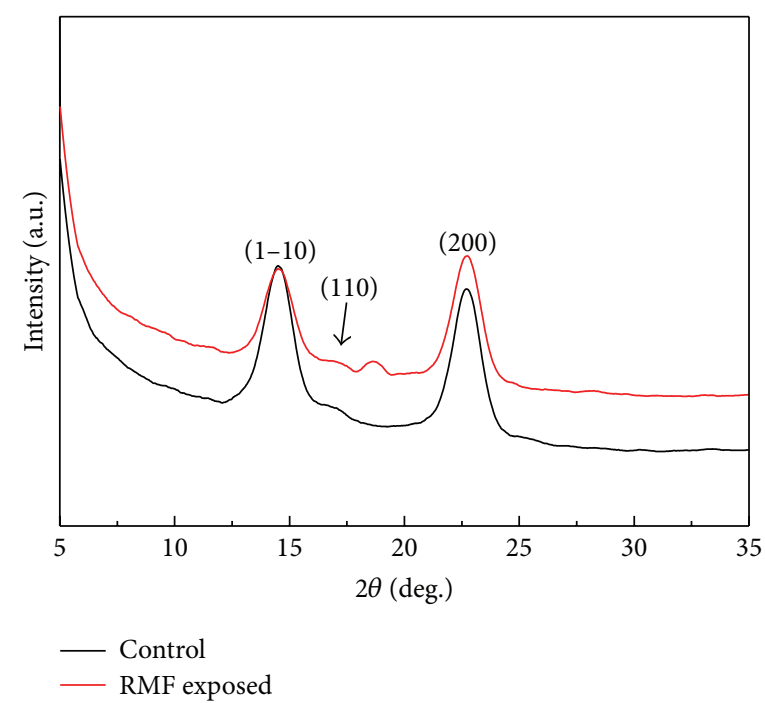

(c)

FIGURE 5: XRD patterns of BC pellicles obtained after (a) 3, (b) 5, and (c) 7 days of culture.

the signal at $1042 \mathrm{~cm}^{-1}$ corresponds to the amorphous form of cellulose. The analyzed spectra showed also the intense cross-peaks observed outside the diagonal axis referring to the above-mentioned signals and indicating that there have been changes in crystallinity in these regions [43].

3.2. X-Ray Diffraction Analyses. The XRD patterns of the $\mathrm{BC}$ synthesized in the control conditions and under RMF exposure are presented in Figure 5. From this figure it is clearly seen that XRD patterns of all studied samples exhibited three diffraction peaks at $2 \theta$ value of around $14.6^{\circ}, 16.8^{\circ}$, and $22.8^{\circ}$. All those reflections are assigned to the cellulose phase (JCPDS card number 50-2241) and correspond to the diffraction planes of (1-10), (110), and (200), respectively [50].

The average crystallite size calculated for the synthesized samples is shown in Table 2. It can be seen that the crystallites size was not significantly changed when $\mathrm{BC}$ was synthesized in the presence of RMF. Additionally, the time dependence versus the crystallite size for both control and RMF exposed samples has been detected. The longer growth time induced the reduction of the crystallites size.

3.3. Structure of Bacterial Cellulose. The SEM micrographs showing the BC structure are presented in Figure 6. From the comparison of the $\mathrm{BC}$ fibers orientation, significant differences in the samples incubated for longer period were revealed. It was shown that the structure of the cellulose after 5 and 7 days was more compacted (dense), in the case of both RMF exposed and control BC, in comparison to the respective samples produced in 3 days. It was also observed that application of the RMF during BC synthesis resulted in the long fiber formation. This effect was enhanced in 

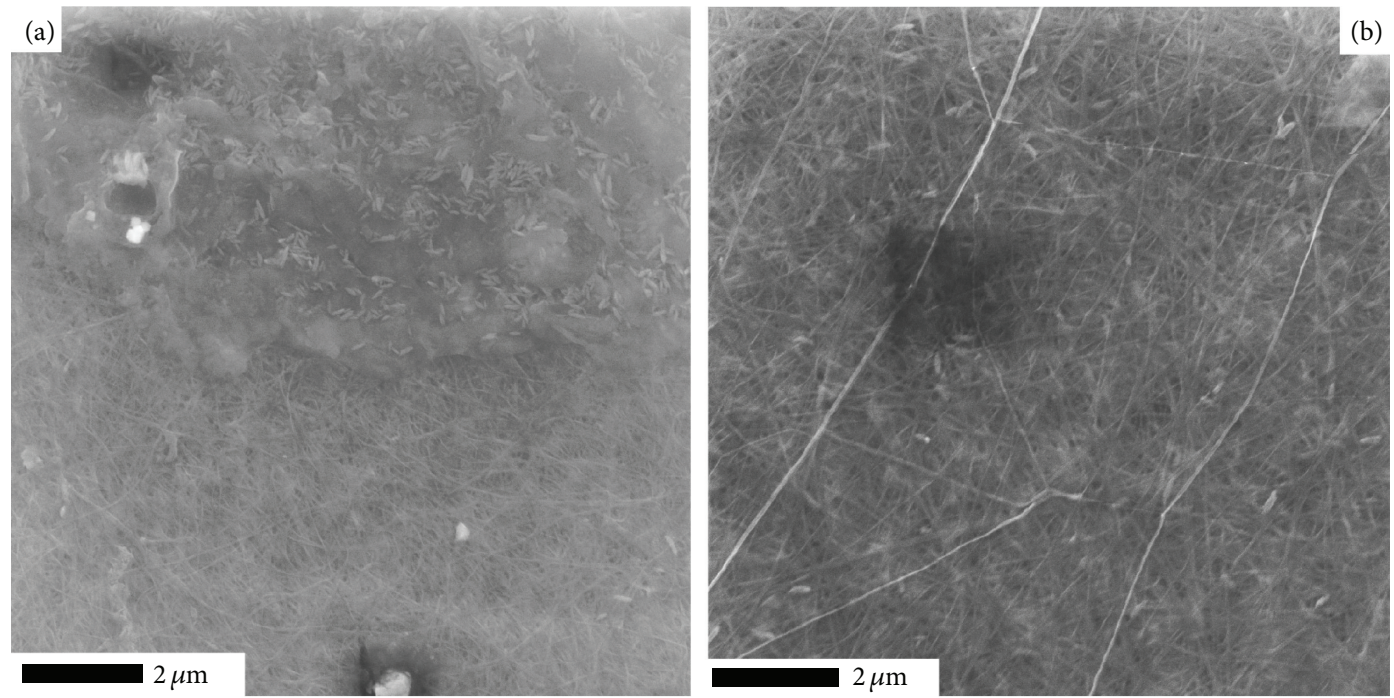

(c)

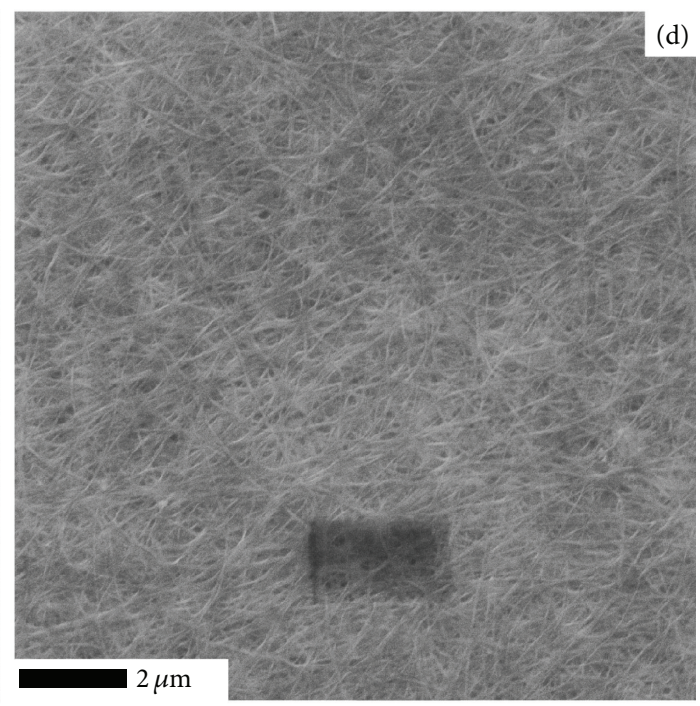

(e)
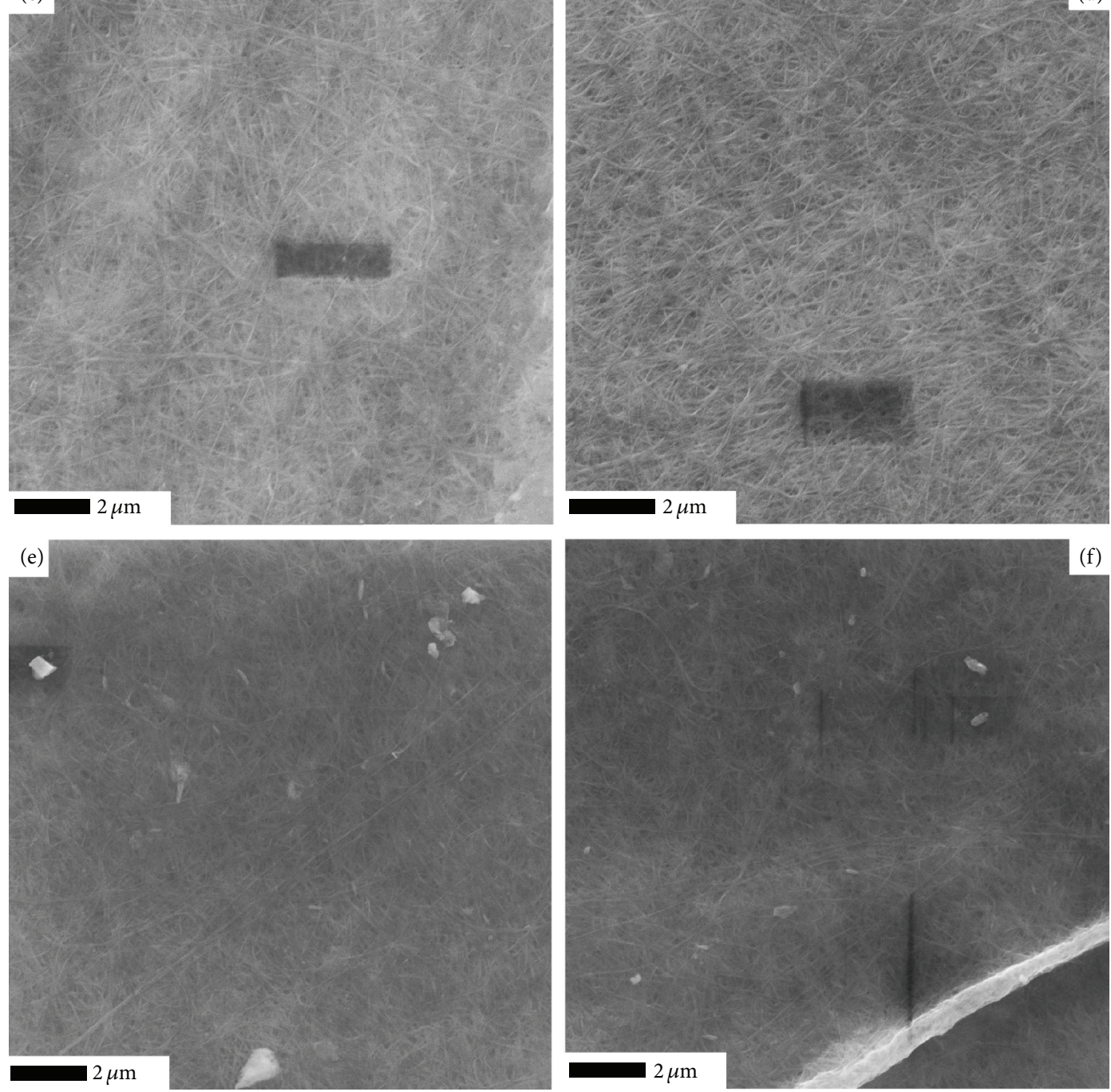

FIGURE 6: Scanning electron microscopy images of control (a, c, e) and RMF exposed (b, d, f) BC obtained after 3, 5, and 7 days of cultivation, respectively. 


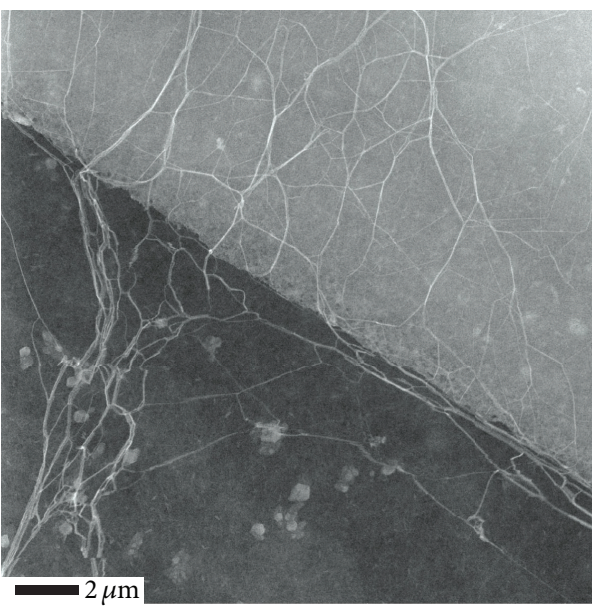

(a)

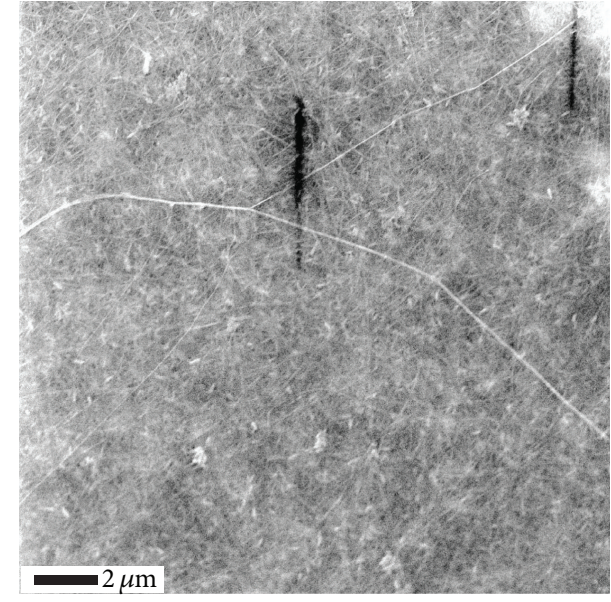

(b)

FIGURE 7: Scanning electron microscopy images of long BC fibers synthesized for 3 days under RMF exposition.

TABLE 2: Average crystallite size of control and RMF exposed BC samples.

\begin{tabular}{lcc}
\hline Sample & Days of BC synthesis & Average crystallite size [nm] \\
\hline RMF exposed & 3 & 8.4 \\
Control & & 7.8 \\
RMF exposed & 5 & 6.7 \\
Control & & 7.0 \\
RMF exposed & 7 & 6.4 \\
Control & & 6.9 \\
\hline
\end{tabular}

the sample after 3 days of the culture under RMF influence (Figure 7). The difference between the length of the fibers after further time extension is less noticeable due to the high structure density and entanglement of the fibers. However, it is not excluded that the longer fibers are also present in the samples after 5 and 7 days of growth. They exhibit similar structure of high density with long, tangled fibers.

3.4. Swelling and Water Retention Characteristics. The cellulose obtained in the RMF was characterized by higher ability to swell by water accumulation as compared to the cellulose obtained under the standard conditions (Figure 8). It was also recorded that swelling properties of $\mathrm{BC}$ decreased with time in the similar manner for both control BC and BC from RMF exposed cultures. The difference between the swelling ratio calculated for the $\mathrm{BC}$ obtained from different culture conditions was $26 \%, 18 \%$, and $16 \%$ for BC synthesized for 3 , 5 , and 7 days, respectively.

In order to study the water holding capacity of the samples in great detail, TGA analysis was performed from room temperature to $120^{\circ} \mathrm{C}$. The control BC exhibited $94 \%, 98 \%$, and $100 \%$ of the weight loss for the samples prepared in 3, 5, and 7 days, respectively (Figure 9(a)). In the case of the BC samples produced in the presence of RMF, the percentage of sample weight loss was $87 \%, 89 \%$, and $99 \%$, for 3,5 , and 7 days, correspondingly (Figure 9(b)).

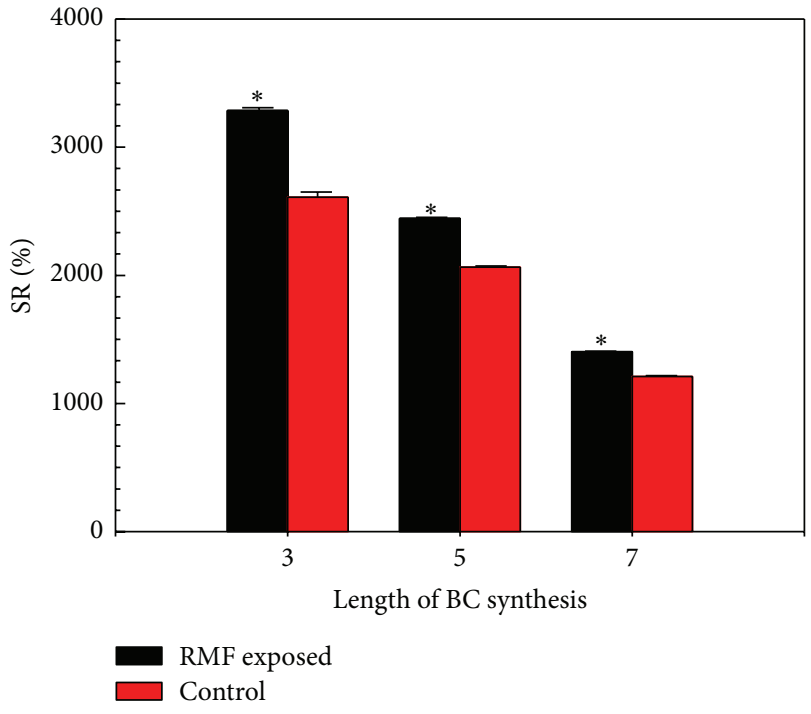

FIGURE 8: The swelling behavior of control and RMF exposed BC pellicles. Data are expressed as percentage of swelling ratio (\%SR) calculated by (1) and presented as a mean \pm standard error of the mean (SEM). *Statistically significant difference between RMF exposed BC and control BC (Student's $t$-test, $P<0.05$ ).

\section{Discussion}

Currently, there is abundant evidence that various types of MFs affect the functional processes of the microorganisms and influence their biotechnological potential [51]. The studies on the use of MFs in the biotechnological process conducted to date have concerned mostly the SMF, whereas the RMF still remains unexplored [31, 52]. However, their effects on microorganisms and substances produced by them can differ due to the different nature of the SMF and the RMF. It should be noticed that the SMF does not vary over time or changes slowly and does not have frequency [53]. In contrast, the RMF changes over time and can be characterized 


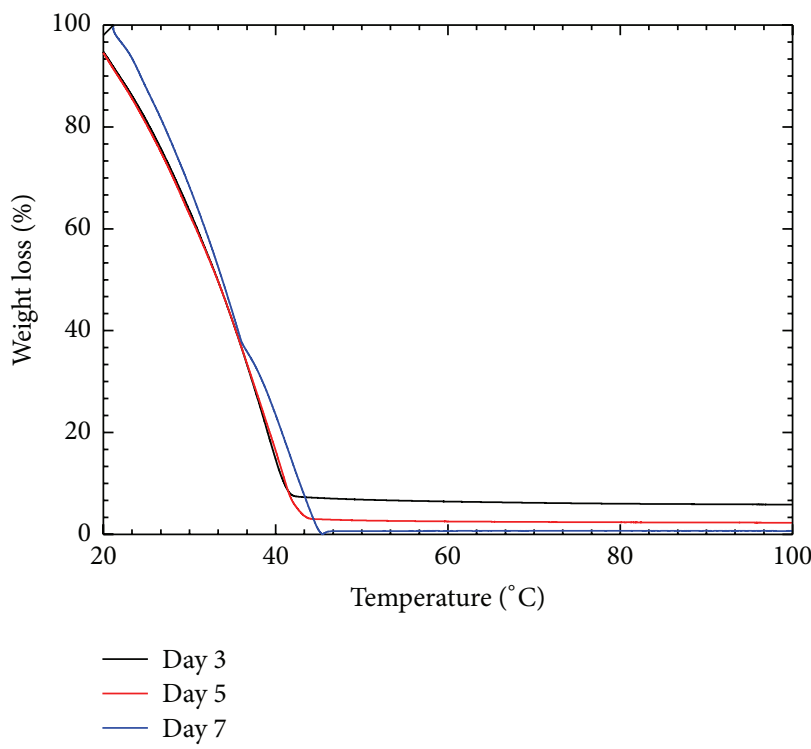

(a)

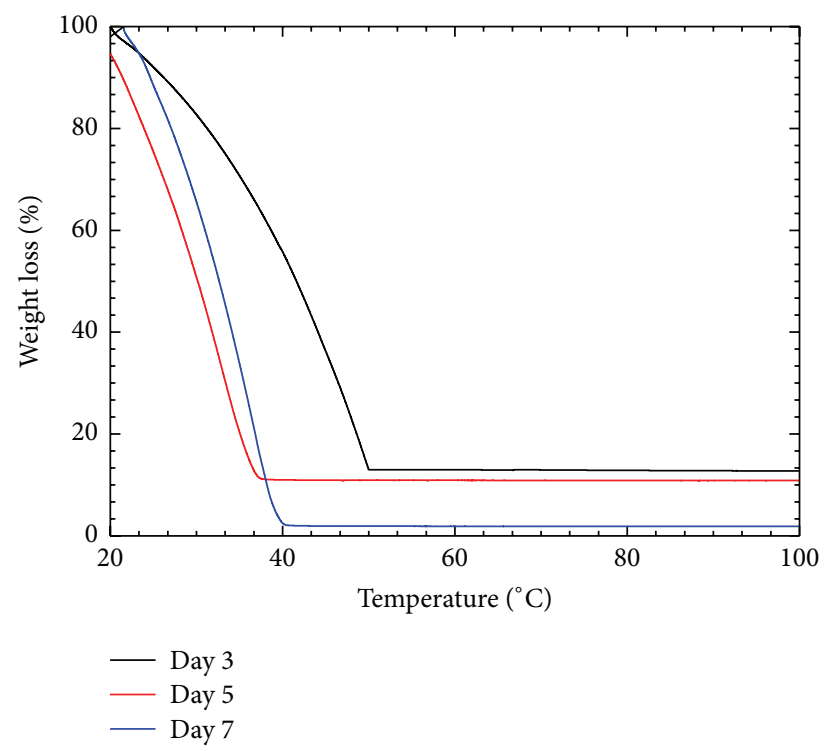

(b)

FIGURE 9: The water holding capacity calculated for the (a) control and (b) RMF exposed BC pellicles.

by its frequency [54]. The effect of the magnetic stimulation on bacteria depends on the magnetic frequency, the magnetic induction, and the time of exposure. In previous studies we proved that the exposure to the RMF depended on those parameters and influenced growth and metabolic activity of the different microorganisms $[39,40]$.

Biocellulose produced by G. xylinus contains more than $90 \%$ of water [55]. The water resides inside the BC pores and is bound to the cellulose fibrils through hydrogen bonding [56]. The swelling in water capacity and water release rate are considered the most important properties which are directly involved in the biomedical applications of $\mathrm{BC}$ as a dressing material [57]. Both parameters have a direct relation with the $\mathrm{BC}$ fibril arrangement [57]. The $\mathrm{BC}$ microstructure, in turn, determines the usefulness of this material as carrier supports for the immobilization of microorganisms and proteins [58, 59]. The current study revealed that the cellulose obtained under RMF influences both water absorption and density of microfibrils. However, these effects strictly depended on the synthesis time and exposure to RMF time.

Gretz et al. [60] demonstrated that magnetically altered $\mathrm{BC}$ was characterized by the greater capacity of water absorption, greater chemical reactivity, lower density, lower tensile strength, and greater surface area. These authors suggested that the altered cellulose produced by G. xylinus is a result of direct magnetic interaction with $\beta$-glucan during its crystallization. Previous studies have also revealed that cellulose nanocrystals have a negative diamagnetic anisotropy [35] and that they are oriented perpendicularly to the magnetic field [27-30]. Therefore, it was suggested that MFs may be applied to control the cellulose nanocrystals orientation and its influence on $\mathrm{BC}$ cellulose fibrils crystal network formation rate $[37,38]$. In this study, changes in the intensity of the ATR-FTIR spectra in the region from $900 \mathrm{~cm}^{-1}$ to $1150 \mathrm{~cm}^{-1}$
(2D spectra) were characterized by higher dynamics in the case of the BC samples from the cultures exposed to RMF. This may suggest that higher intensity of the changes in the molecular structure of cellulose may have an impact on the rate of its microfibrils crystallization. Unfortunately, due to the complexity of this process, it is difficult to determine unequivocally which factor is crucial. BC synthesis process consists of two stages, polymerization and crystallization. The polymerization step is catalyzed by the cellulose synthase complex. After extraction of the polyglucan outside of the bacterial cell, the association of the chains and the formation of the cellulose microfibril crystalline structure occurs. The stabilization of the highly ordered BC structure is dependent on the hydrophobic interactions and hydrogen bonds formed between hydroxyl groups of neighboring $\beta$ glucan chains [61,62]. Recent studies have indicated an important role of water molecules in the process of cellulose crystalline structure formation. It can be assumed that water can be involved in the formation of the crystal structure of cellulose, facilitating (catalyzing) the alignment of $\beta$-glucans chains through hydrogen-bonded bridging [63]. In this case, RMF may have a significant impact on the formation of hydrogen-bonded bridging. Previous studies have confirmed the influence of SMF on physicochemical properties of water. It was shown that SMF can reduce the surface tension of water and increase its viscosity. The disorder in the ability of water molecules to form hydrogen bonds stabilizes its crystal structure [64-66]. These changes are likely to have an impact on the rate of $\mathrm{BC}$ crystalline structure formation and its quality. The observation from the SEM examination revealed that the structure of the cellulose after 5 and 7 days was more compacted (dense), in case of both RMF exposed and control $\mathrm{BC}$, in comparison to the respective samples produced in 3 days. Cellulose chains forming subelementary fibrils are 
extruded out of the surface of the bacterial cell into the culture medium. These subfibrils aggregate together forming larger microfibrils [67]. Therefore the density of BC increases with culture time due to the secretion of more fibrils with the passage of time [68]. It was also observed that application of the RMF during BC synthesis resulted in the long fiber formation and consequently more tangled and compacted fibrous structure. This effect was especially clearly seen after 3 days of culture under RMF influence (long fiber appearance) and after 5 days with and without RMF exposure (higher density). The observed changes in the morphology of the samples can be responsible for the water swelling and water holding properties observed for cellulose from RMF exposed cultures. In the present study, the BC obtained after 3 days presented the most interesting behavior of water absorption. The observation was confirmed for both control and RMF exposed BC and obviously it was mainly related to the loose structure of young cellulose matrix. However, the cellulose obtained in the presence of RMF showed 26\% higher ability to swell in water in comparison to the control cellulose. Similar results were obtained in our previous studies [31], in which, as a result of exposure of G. xylinus cultures to RMF during 3 days cultivation, the obtained $\mathrm{BC}$ was characterized by increased water absorption by $23 \%$ as compared to the unexposed control sample. Our observation also agreed with the previous results reported by Al-Shamary and AlDarwash [69] in which the density of BC increased during the cultivation, whereas water capacity decreased due to the increased secretion of the fibrils with time. However, it should be noticed that, in the case of our study, cellulose synthetized for 7 days in RMF was still characterized by significantly higher water adsorption capacity (16\%) as compared to the unexposed control polymer. Moreover, from a comparison of the current and the previous studies, which involved the use of different G. xylinus strains, it can be concluded that the effect caused by magnetic field seems to be independent of the particular strain. However, this assumption should be further confirmed with a larger number of different G. xylinus strains.

The high ability to swell in water of BC could arise from differences in the material microstructure due to the different culture conditions and time of exposure to RMF. The water absorption capacity depends especially on the number and size of pores on the polymer surface. It was reported by several authors that the loose fibril arrangement and large size of pores enhance the water capacity of BC [70, 71]. It is considered that closely arranged microfibrils bind the water molecules more efficiently due to the stronger hydrogen bonding interactions, as compared to the loosely arranged microfibrils [72, 73]. Furthermore, it was demonstrated that more water can be retained due to the larger surface area provided by thinner and longer fibers [74]. In the present study, it was also shown that RMF exposed BC released water slightly slower and required the highest temperature to release water molecules as compared to the unexposed controls. This observation is particularly surprising considering looser structure of these BC samples. In this case, increased ability to retain water might be explained by the size of pores in the investigated BC samples. It was reported by Ul-Islam et al. [57] that cellulose membranes with smaller pore sizes can retain water in the matrix for longer times. Although the porosity of BC was not examined in our study, it can be assumed that the exposure to the RMF might result in formation of smaller pores in these samples, protecting the water from evaporation.

\section{Conclusions}

Summarizing, the current study intends to produce BC with altered morphology, physicochemical properties, the water retention and holding capacity synthesized in $G$. xylinus cultures exposed to the RMF of $50 \mathrm{~Hz}$ frequency, and magnetic induction of $34 \mathrm{mT}$ for 3, 5, and 7 days. It was observed by SEM that application of the RMF during BC synthesis influenced its nano- and microscale structure. The RMF altered cellulose, regardless of the synthesis time, was characterized by significantly higher water adsorption capacity as compared to unexposed control samples. The physicochemical properties of BC studied by ATR-FTIR and XRD were similar regardless of the culture conditions employed. The only differences found in the synchronous $2 \mathrm{D}$ correlation of ATR-FTIR spectra indicated the impact of RMF exposure on the dynamics of the formation of $\mathrm{BC}$ microfibers crystallinity. Therefore it can be concluded that the impact of the RMF which allows improving the useful properties of water behavior in $\mathrm{BC}$ while not compromising the remaining properties of the polymer may provide a novel technique for altering cellulose biogenesis and when fully developed may find application in the multiple biotechnological applications.

\section{Conflict of Interests}

The authors declare that there is no conflict of interests regarding the publication of this paper.

\section{Acknowledgment}

This study was supported by the National Centre for Research and Development in Poland (Grant no. LIDER/011/221/L5/13/NCBR/2014).

\section{References}

[1] D. Mikkelsen, B. M. Flanagan, G. A. Dykes, and M. J. Gidley, "Influence of different carbon sources on bacterial cellulose production by Gluconacetobacter xylinus strain ATCC 53524," Journal of Applied Microbiology, vol. 107, no. 2, pp. 576-583, 2009.

[2] W. K. Czaja, D. J. Young, M. Kawecki, and R. M. Brown Jr., "The future prospects of microbial cellulose in biomedical applications," Biomacromolecules, vol. 8, no. 1, pp. 1-12, 2007.

[3] D. R. Ruka, G. P. Simon, and K. M. Dean, "Altering the growth conditions of Gluconacetobacter xylinus to maximize the yield of bacterial cellulose," Carbohydrate Polymers, vol. 89, no. 2, pp. 613-622, 2012.

[4] R. Jonas and L. F. Farah, "Production and application of microbial cellulose," Polymer Degradation and Stability, vol. 59, no. 1-3, pp. 101-106, 1998. 
[5] W. K. Wan and L. E. Millon, "Poly(vinyl alcohol)-bacterial cellulose nanocomposite," US Patent Applications, US 2005037082 A1 16, 2005.

[6] A. M. Sokolnicki, R. J. Fisher, T. P. Harrah, and D. L. Kaplan, "Permeability of bacterial cellulose membranes," Journal of Membrane Science, vol. 272, no. 1-2, pp. 15-27, 2006.

[7] P. A. Charpentier, A. Maguire, and W.-K. Wan, "Surface modification of polyester to produce a bacterial cellulose-based vascular prosthetic device," Applied Surface Science, vol. 252, no. 18, pp. 6360-6367, 2006.

[8] V. I. Legeza, V. P. Galenko-Yaroshevskii, E. V. Zinov'ev et al., "Effects of new wound dressings on healing of thermal burns of the skin in acute radiation disease," Bulletin of Experimental Biology and Medicine, vol. 138, no. 3, pp. 311-315, 2004.

[9] W. Czaja, A. Krystynowicz, S. Bielecki, and R. M. Brown Jr., "Microbial cellulose-the natural power to heal wounds," Biomaterials, vol. 27, no. 2, pp. 145-151, 2006.

[10] H. Bäckdahl, G. Helenius, A. Bodin et al., "Mechanical properties of bacterial cellulose and interactions with smooth muscle cells," Biomaterials, vol. 27, no. 9, pp. 2141-2149, 2006.

[11] W. K. Wan, J. L. Hutter, L. Milion, and G. Guhados, "Bacterial cellulose and its nanocomposites for biomedical applications," ACS Symposium Series, vol. 938, pp. 221-241, 2006.

[12] Y.-J. Choi, Y. Ahn, M.-S. Kang, H.-K. Jun, I. S. Kim, and S.H. Moon, "Preparation and characterization of acrylic acidtreated bacterial cellulose cation-exchange membrane," Journal of Chemical Technology and Biotechnology, vol. 79, no. 1, pp. 7984, 2004.

[13] R. M. Brown, "Microbial cellulose as a building block resource for specialty products and processes therefore," PCT International Applications, WO 8912107 A1 (1989) 37, 1993.

[14] K. Watanabe, Y. Eto, S. Takano, S. Nakamori, H. Shibai, and S. Yamanaka, "A new bacterial cellulose substrate for mammalian cell culture," Cytotechnology, vol. 13, no. 2, pp. 107-114, 1993.

[15] W. Hu, S. Liu, S. Chen, and H. Wang, "Preparation and properties of photochromic bacterial cellulose nanofibrous membranes," Cellulose, vol. 18, no. 3, pp. 655-661, 2011.

[16] W. Hu, S. Chen, Z. Yang, L. Liu, and H. Wang, "Flexible electrically conductive nanocomposite membrane based on bacterial cellulose and polyaniline," Journal of Physical Chemistry B, vol. 115, no. 26, pp. 8453-8457, 2011.

[17] W. Zhang, S. Chen, W. Hu et al., "Facile fabrication of flexible magnetic nanohybrid membrane with amphiphobic surface based on bacterial cellulose," Carbohydrate Polymers, vol. 86, no. 4, pp. 1760-1767, 2011.

[18] X. Zhang, W. Chen, Z. Lin, and J. Shen, "Photocatalytic degradation of a methyl orange wastewater solution using titanium dioxide loaded on bacterial cellulose," Synthesis and Reactivity in Inorganic, Metal-Organic and Nano-Metal Chemistry, vol. 41, no. 9, pp. 1141-1147, 2011.

[19] K.-Y. Lee, G. Buldum, A. Mantalaris, and A. Bismarck, "More than meets the eye in bacterial cellulose: biosynthesis, bioprocessing, and applications in advanced fiber composites," Macromolecular Bioscience, vol. 14, no. 1, pp. 10-32, 2014.

[20] W. Czaja, D. Romanovicz, and R. m. Brown," "Structural investigations of microbial cellulose produced in stationary and agitated culture," Cellulose, vol. 11, no. 3, pp. 403-411, 2004.

[21] N. Suwannapinunt, J. Burakorn, and S. Thaenthanee, "Effect of culture conditions on bacterial cellulose (BC) production from Acetobacter xylinum TISTR976 and physical properties of BC parchment paper," Suranaree Journal of Science and Technology, vol. 14, no. 4, pp. 357-365, 2007.
[22] M. Hornung, M. Ludwig, A. M. Gerrard, and H.-P. Schmauder, "Optimizing the production of bacterial cellulose in surface culture: evaluation of substrate mass transfer influences on the bioreaction (part 1)," Engineering in Life Sciences, vol. 6, no. 6, pp. 537-545, 2006.

[23] M. Seifert, S. Hesse, V. Kabrelian, and D. Klemm, "Controlling the water content of never dried and reswollen bacterial cellulose by the addition of water-soluble polymers to the culture medium," Journal of Polymer Science, Part A: Polymer Chemistry, vol. 42, no. 3, pp. 463-470, 2004.

[24] Z. Yan, S. Chen, H. Wang, B. Wang, and J. Jiang, "Biosynthesis of bacterial cellulose/multi-walled carbon nanotubes in agitated culture," Carbohydrate Polymers, vol. 74, no. 3, pp. 659-665, 2008.

[25] S.-S. Wong, S. Kasapis, and Y. M. Tan, "Bacterial and plant cellulose modification using ultrasound irradiation," Carbohydrate Polymers, vol. 77, no. 2, pp. 280-287, 2009.

[26] S.-S. Wong, S. Kasapis, and D. Huang, "Molecular weight and crystallinity alteration of cellulose via prolonged ultrasound fragmentation," Food Hydrocolloids, vol. 26, no. 2, pp. 365-369, 2012.

[27] J. Sugiyama, H. Chanzy, and G. Maret, "Orientation of cellulose microcrystals by strong magnetic fields," Macromolecules, vol. 25, no. 16, pp. 4232-4234, 1992.

[28] P. G. de Gennes and J. Prost, The Physics of Liquid Crystals, Clarendon Press, Oxford, UK, 1993.

[29] J. F. Revol, L. Godbout, X.-M. Dong, D. G. Gray, H. Chanzy, and G. Maret, "Chiral nematic suspensions of cellulose crystallites; phase separation and magnetic field orientation," Liquid Crystals, vol. 16, no. 1, pp. 127-134, 1994.

[30] F. Kimura, T. Kimura, M. Tamura, A. Hirai, M. Ikuno, and F. Horii, "Magnetic alignment of the chiral nematic phase of a cellulose microfibril suspension," Langmuir, vol. 21, no. 5, pp. 2034-2037, 2005.

[31] K. Fijałkowski, A. Żywicka, R. Drozd et al., "Modification of bacterial cellulose through exposure to the rotating magnetic field," Carbohydrate Polymers, vol. 133, pp. 52-60, 2015.

[32] R. W. Hunt, A. Zavalin, A. Bhatnagar, S. Chinnasamy, and K. C. Das, "Electromagnetic biostimulation of living cultures for biotechnology, biofuel and bioenergy applications," International Journal of Molecular Sciences, vol. 10, no. 10, pp. 45154558, 2009.

[33] E. S. A. Gaafar, M. S. Hanafy, E. Y. Tohamy, and M. H. Ibranhim, "The effect of electromagnetic field on protein molecular structure of E. coli and its pathogenesis," Romanian Journal of Biophysics, vol. 18, no. 2, pp. 145-169, 2008.

[34] V. Anton-Leberre, E. Haanappel, N. Marsaud et al., "Exposure to high static or pulsed magnetic fields does not affect cellular processes in the yeast Saccharomyces cerevisiae," Bioelectromagnetics, vol. 31, no. 1, pp. 28-38, 2010.

[35] E. D. Cranston and D. G. Gray, "Formation of cellulose-based electrostatic layer-by-layer films in a magnetic field," Science and Technology of Advanced Materials, vol. 7, no. 4, pp. 319-321, 2006.

[36] T. Kimura, T. Kamioka, and S. Kuga, "Filtration-assisted magnetic micropatterning of bacterial cellulose," Polymer Journal, vol. 39, no. 11, pp. 1199-1201, 2007.

[37] M. Park, S. Park, and J. Hyun, "Use of magnetic nanoparticles to manipulate the metabolic environment of bacteria for controlled biopolymer synthesis," ACS Applied Materials and Interfaces, vol. 4, no. 10, pp. 5114-5117, 2012. 
[38] J. P. F. Lagerwall, C. Schütz, M. Salajkova et al., "Cellulose nanocrystal-based materials: from liquid crystal self-assembly and glass formation to multifunctional thin films," NPG Asia Materials, vol. 6, article e80, 2014.

[39] K. Fijałkowski, P. Nawrotek, M. Struk, M. Kordas, and R. Rakocz, "The effects of rotating magnetic field on growth rate, cell metabolic activity and biofilm formation by Staphylococcus aureus and Escherichia coli," Journal of Magnetics, vol. 18, no. 3, pp. 289-296, 2013.

[40] P. Nawrotek, K. Fijałkowski, M. Struk, M. Kordas, and R. Rakoczy, "Effects of $50 \mathrm{~Hz}$ rotating magnetic field on the viability of Escherichia coli and Staphylococcus aureus," Electromagnetic Biology and Medicine, vol. 33, no. 1, pp. 29-34, 2014.

[41] S. Hesse and T. Kondo, "Behavior of cellulose production of Acetobacter xylinum in ${ }^{13} \mathrm{C}$-enriched cultivation media including movements on nematic ordered cellulose templates," Carbohydrate Polymers, vol. 60, no. 4, pp. 457-465, 2005.

[42] Y. Liu, G. Gamble, and D. Thibodeaux, "Two-dimensional attenuated total reflection infrared correlation spectroscopy study of the desorption process of water-soaked cotton fibers," Applied Spectroscopy, vol. 64, no. 12, pp. 1355-1363, 2010.

[43] Y. Liu, D. Thibodeaux, G. Gamble, P. Bauer, and D. VanDerveer, "Comparative investigation of fourier transform infrared (FTIR) spectroscopy and X-ray diffraction (XRD) in the determination of cotton fiber crystallinity," Applied Spectroscopy, vol. 66, no. 8, pp. 983-986, 2012.

[44] Y. Kataoka and T. Kondo, "Quantitative analysis for the cellulose I $\alpha$ crystalline phase in developing wood cell walls," International Journal of Biological Macromolecules, vol. 24, no. 1, pp. 37-41, 1999.

[45] M. Poletto, H. L. Ornaghi Jr., and A. J. Zattera, "Native cellulose: structure, characterization and thermal properties," Materials, vol. 7, no. 9, pp. 6105-6119, 2014.

[46] R. H. Atalla, "Celluloses," in Carbohydrates and Their Derivatives Including Tannins, Cellulose, and Related Lignings, B. M. Pinto, Ed., vol. 3 of Comprehensive Natural Products Chemistry, pp. 529-598, Elsevier, Amsterdam, The Netherlands, 1999.

[47] Y. Park, I. Noda, and Y. M. Jung, “Two-dimensional correlation spectroscopy in polymer study," Frontiers in Chemistry, vol. 3, article 14, 2015.

[48] I. Noda, "Generalized two-dimensional correlation method applicable to infrared, Raman, and other types of spectroscopy," Applied Spectroscopy, vol. 47, no. 9, pp. 1329-1336, 1993.

[49] V. G. Gregoriou and M. S. Braiman, Vibrational Spectroscopy of Biological and Polymeric Materials, CRC Press, Taylor \& Francis Group, Boca Raton, Fla, USA, 2006.

[50] J.-H. Pang, X. Liu, M. Wu, Y.-Y. Wu, X.-M. Zhang, and R.-C. Sun, "Fabrication and characterization of regenerated cellulose films using different ionic liquids," Journal of Spectroscopy, vol. 2014, Article ID 214057, 8 pages, 2014.

[51] L. Fojt, L. Strašák, V. Vetterl, and J. Šmarda, "Comparison of the low-frequency magnetic field effects on bacteria Escherichia coli, Leclercia adecarboxylata and Staphylococcus aureus," Bioelectrochemistry, vol. 63, no. 1-2, pp. 337-341, 2004.

[52] J. Hristov, "Magnetic field assisted fluidization-a unified approach. Part 8. Mass transfer: magnetically assisted bioprocesses," Reviews in Chemical Engineering, vol. 26, no. 3-4, pp. 55-128, 2010.

[53] S. Shanmugapriya, A. Sarumathi, and N. Saravanan, "Study of lipid profile changes and histopathology examination of heart under immobilization stress with static magnetic field exposure in rats," International Journal of Environmental Biology, vol. 2, pp. 41-49, 2012.

[54] R. Rakoczy, "Mixing energy investigations in a liquid vessel that is mixed by using a rotating magnetic field," Chemical Engineering and Processing: Process Intensification, vol. 66, pp. 1-11, 2013.

[55] N. Pa’E, N. I. A. Hamid, N. Khairuddin et al., "Effect of different drying methods on the morphology, crystallinity, swelling ability and tensile properties of nata de coco," Sains Malaysiana, vol. 43, no. 5, pp. 767-773, 2014.

[56] K. Gelin, A. Bodin, P. Gatenholm, A. Mihranyan, K. Edwards, and M. Strømme, "Characterization of water in bacterial cellulose using dielectric spectroscopy and electron microscopy," Polymer, vol. 48, no. 26, pp. 7623-7631, 2007.

[57] M. Ul-Islam, T. Khan, and J. K. Park, "Water holding and release properties of bacterial cellulose obtained by in situ and ex situ modification," Carbohydrate Polymers, vol. 88, no. 2, pp. 596603, 2012.

[58] S.-C. Wu and Y.-K. Lia, "Application of bacterial cellulose pellets in enzyme immobilization," Journal of Molecular Catalysis B: Enzymatic, vol. 54, no. 3-4, pp. 103-108, 2008.

[59] N. M. N. Ton, M. D. Nguyen, T. T. H. Pham, and V. V. M. Le, "Influence of initial $\mathrm{pH}$ and sulfur dioxide content in must on wine fermentation by immobilized yeast in bacterial cellulose," International Food Research Journal, vol. 17, no. 3, pp. 743-749, 2010.

[60] M. R. Gretz, D. B. Folsom, and R. M. Brown Jr., "Cellulose biogenesis in bacteria and higher plants is disrupted by magnetic fields," Naturwissenschaften, vol. 76, no. 8, pp. 380-383, 1989.

[61] M. Benziman, C. H. Haigler, and R. M. Brown Jr., "Cellulose biogenesis: polymerization and crystallization are coupled processes in Acetobacter xylinum," Proceedings of the National Academy of Sciences of the United States of America, vol. 77, no. 11, pp. 6678-6682, 1980.

[62] J. L. W. Morgan, J. Strumillo, and J. Zimmer, "Crystallographic snapshot of cellulose synthesis and membrane translocation," Nature, vol. 493, no. 7431, pp. 181-186, 2013.

[63] D. P. Shelton, "Long-range orientation correlation in water," The Journal of Chemical Physics, vol. 141, no. 22, Article ID 224506, 2014.

[64] X.-F. Pang and D. Bo, "The changes of macroscopic features and microscopic structures of water under influence of magnetic field," Physica B: Condensed Matter, vol. 403, no. 19-20, pp. 35713577, 2008.

[65] A. Szcześ, E. Chibowski, L. Hołysz, and P. Rafalski, "Effects of static magnetic field on water at kinetic condition," Chemical Engineering and Processing: Process Intensification, vol. 50, no. 1, pp. 124-127, 2011.

[66] E. J. L. Toledo, T. C. Ramalho, and Z. M. Magriotis, "Influence of magnetic field on physical-chemical properties of the liquid water: insights from experimental and theoretical models," Journal of Molecular Structure, vol. 888, no. 1-3, pp. 409-415, 2008.

[67] F. Horii, H. Yamamoto, and A. Hirai, "Microstructural analysis of microfibrils of bacterial cellulose," Macromolecular Symposia, vol. 120, pp. 197-205, 1997.

[68] W. Tang, S. Jia, Y. Jia, and H. Yang, "The influence of fermentation conditions and post-treatment methods on porosity of bacterial cellulose membrane," World Journal of Microbiology and Biotechnology, vol. 26, no. 1, pp. 125-131, 2010. 
[69] E. E. Al-Shamary and A. K. Al-Darwash, "Influence of fermentation condition and alkali treatment on the porosity and thickness of bacterial cellulose membranes," The Online Journal of Science and Technology, vol. 3, no. 2, 2013.

[70] Y. Dahman, "Nanostructured biomaterials and biocomposites from bacterial Cellulose nanofibers," Journal of Nanoscience and Nanotechnology, vol. 9, no. 9, pp. 5105-5122, 2009.

[71] J. Guo and J. M. Catchmark, "Surface area and porosity of acid hydrolyzed cellulose nanowhiskers and cellulose produced by Gluconacetobacter xylinus," Carbohydrate Polymers, vol. 87, no. 2, pp. 1026-1037, 2012.

[72] H. Ougiya, K. Watanabe, T. Matsumura, and F. Yoshinaga, "Relationship between suspension properties and fibril structure of disintegrated bacterial cellulose," Bioscience, Biotechnology and Biochemistry, vol. 62, no. 9, pp. 1714-1719, 1998.

[73] N. Shah, J. H. Ha, and J. K. Park, "Effect of reactor surface on production of bacterial cellulose and water soluble oligosaccharides by Gluconacetobacter hansenii PJK," Biotechnology and Bioprocess Engineering, vol. 15, no. 1, pp. 110-118, 2010.

[74] B. V. Mohite and S. V. Patil, "Physical, structural, mechanical and thermal characterization of bacterial cellulose by $G$. hansenii NCIM 2529," Carbohydrate Polymers, vol. 106, no. 1, pp. 132-141, 2014. 

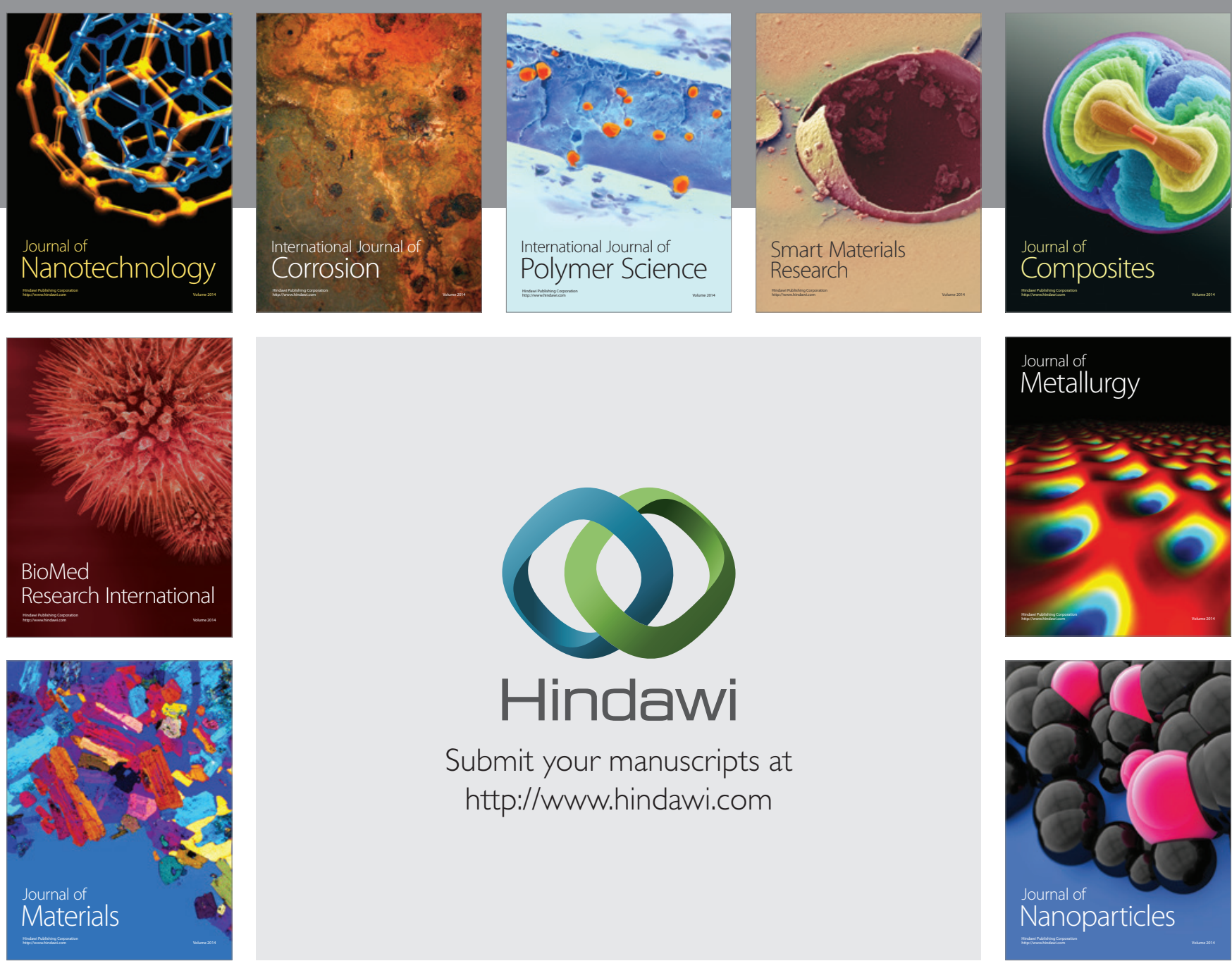

\section{Hindawi}

Submit your manuscripts at

http://www.hindawi.com

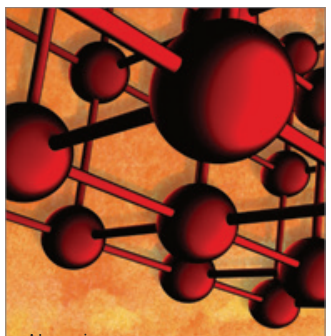

Materials Science and Engineering
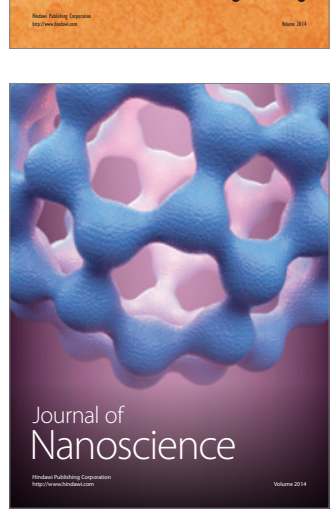
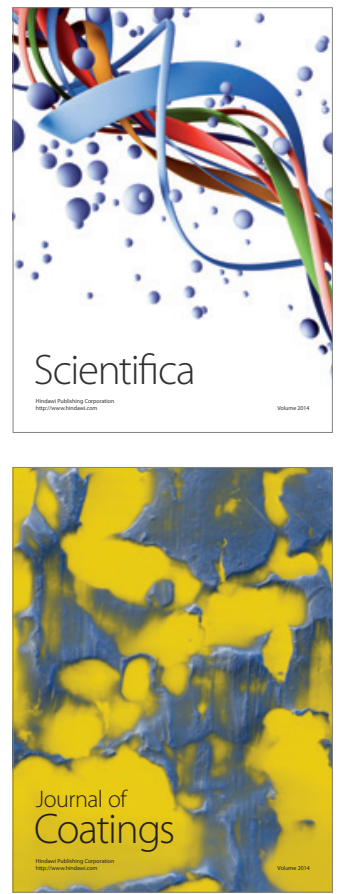
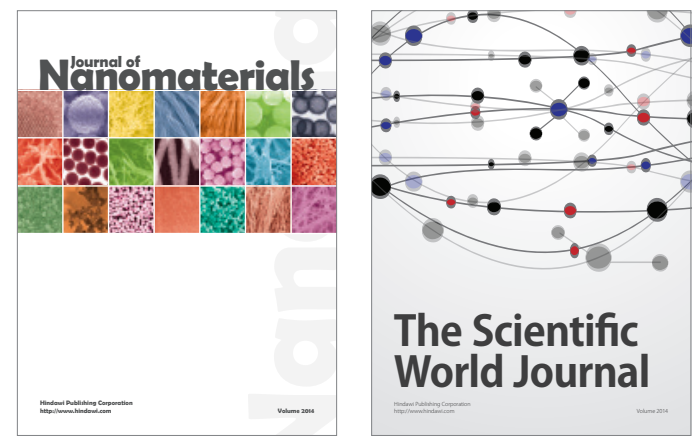

The Scientific World Journal
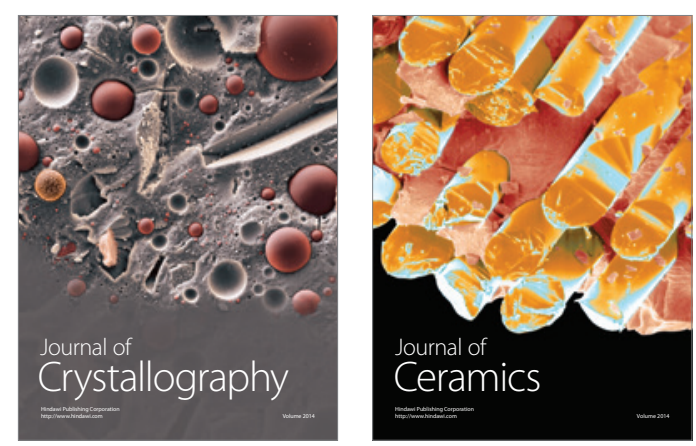
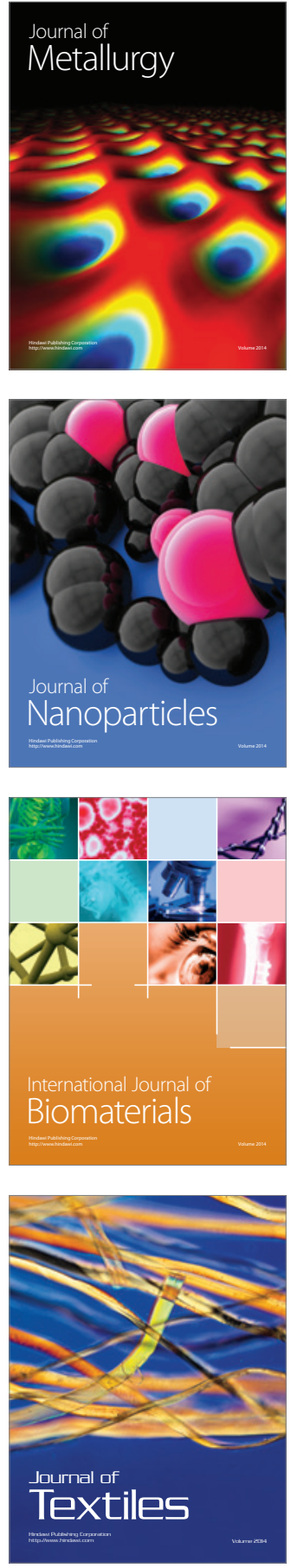